\title{
Obesity Associations with Behavior and Anxiety in Lebanese
} Adolescents

\author{
Mohamad Al-Tannir ${ }^{*}$, Nahla Abou Assi ${ }^{2}$, Amani K Abu-Shaheen ${ }^{1}$ and Youssef Altannir ${ }^{3}$ \\ ${ }^{1}$ Research Center, King Fahad Medical City, Riyadh, Saudi Arabia \\ ${ }^{2}$ Department of Pediatrics, Makassed General Hospital, Beirut, Lebanon \\ ${ }^{3}$ Al-Faisal University, College of Medicine, Riyadh, Saudi Arabia
}

\begin{abstract}
Aim: To evaluate the influence of obesity on physical, social and emotional well-being of a representative sample of Lebanese adolescents.

Methods: A self-administered questionnaire and a behavior checklist were distributed to 700 Lebanese adolescents aged $12-18$ years

Results: A total of 587 were collected (response rate: 69.57\%) of whom 231(47.4\%) were male and 256(52.6\%) were female. Overall, $10.5 \%$ of the adolescents were obese. Activity score, as part of the competence scale, showed that $77(15.9 \%)$ had activity scores below normal. Moreover, borderline scores were shown in 35 (7.1\%) participants, whereas obesity is significantly associated with low level of social activities among female adolescents. There was no statistical significant difference among obese, overweight and normal weight participants of both genders concerning the withdrawal and anxiety 1 depression scales. In conclusion, obesity among Lebanese adolescents is significantly associated with decreased social activity level among females and imposes a health concern for both genders in later years. The alarming increase in obesity in the juvenile population today.
\end{abstract}

\section{Introduction}

Body shape and body weight dissatisfaction have been associated with a plethora of psychological ills from eating disorders to major depression in adolescents (1). The relationship between participation in social activities and body dissatisfaction among adolescents is strong, and the focus on appearance in making self-evaluations has been implicated in the low levels of self-esteem and social activities engagement often observed in adolescence [2-3].

For instance, obesity is one of the primary reasons for bullying in US schools. While weight-related abuse (WRA) is a specific risk factor for disordered eating (binge eating, emotional eating, night eating, and unhealthy weight control) and negative self-perception; disordered eating and negative self-perception are predictive of obesity themselves which puts the adolescent in a vicious cycle [4]. Furthermore, physical inactivity and obesity became more prevalent in affluent societies due to technology advances and adolescent activity changes.

Both obesity and physical inactivity represent modifiable cardiovascular disease (CVD) risk factors and increase substantially during the transition from adolescence to young adulthood. This is an alarming health concern as CVD is the fifth leading cause of death in people ages 18 to 29 . CVD due to obesity has enormous social and financial repercussions; however, many college age students do not see obesity as a personal threat [5].

This could be seen in a previous study on obesity and eating disorders, where two Portuguese case-control studies compared anorexic young women with bulimia nervosa young women. Bulima nervosa group reported significantly higher rates of paternal high expectations, excessive family importance placed on fitness/keeping in shape, and negative consequences due to adolescent overweight and adolescent objective overweight. Ultimately, overweight during adolescence emerged as the most relevant retrospective correlate in the distinction between bulimia nervosa and anorexia participants. Family expectations and the importance placed on keeping in shape were also significant retrospective correlates in the bulimia nervosa group [6].

These factors combined present a challenge as primary care staff is increasingly asked to promote parents awareness on their children being overweight although this has been recognized as a trigger for the onset of an eating disorder and obesity vicious cycle [7]. However, at the same time they are not provided with a healthy diet and exercise plan that fires back; adolescents are then pushed to see themselves as fat, focusing dangerously on food, body and weight. All this leads to dysfunctional eating patterns, loss of control and increased body mass index (BMI).

It has been reported that obesity is the strongest predictive factor to the onset of an eating disorder [8]. The pervasive and universal body and weight-stigma enhances restrictive behavior and creates a vicious circle that leads to a real eating disorder epidemic among young adults [9].

The studies on overweight and obesity in Lebanon are insufficient. Lebanon is a small middle-income country in the Middle East. What makes Lebanon obesity prevalence studies unique is that it has diverse characteristics: a high urbanization rate $(81 \%)$, a high literacy rate $(75 \%)$, and life expectancy approaching 67 years among men and 70.5 years among women $[10,11]$, coupled with westernization and changes in lifestyle in the past several years. Therefore, noncommunicable diseases have already emerged as the leading causes of

*Corresponding Author: Dr. Mohamad Al-Tannir, Chairperson of Clinical and Translational Research Department, King Fahad Medical City, Riyadh 11525, P. O. Box 59046, Saudi Arabia; E-mail: maltannir@kfmc.med.sa

Citation: Al-Tannir M, Assi NA, Abu-Shaheen AK, Altannir Y (2016) Obesity Associations with Behavior and Anxiety in Lebanese Adolescents. Int J Clin Res Trials 1: 104. doi: https://doi.org/10.15344/2456-8007/2016/104

Copyright: (c) 2016 Al-Tannir et al. This is an open-access article distributed under the terms of the Creative Commons Attribution License, which permits unrestricted use, distribution, and reproduction in any medium, provided the original author and source are credited. 
morbidity and mortality [12]. The lack of basic indicators of major chronic disease risk factors such as the distribution of BMI in the population hinders public health planning for intervention and control of these diseases.

Our study presents the consequences of childhood obesity on level of social activities and its association with behavioral problems namely anxiety, which have not yet been thoroughly assessed on a national level (4-5). Therefore, the aim of this study was to evaluate the influence of obesity on physical, social and emotional well-being of a representative sample of Lebanese adolescents.

\section{Materials and Methods}

After having received approval from the Institutional Review Board at Makassed General Hospital,

We randomly approached and invited a representative sample of 700 adolescents over a 5-month period from 10 schools located in all 5 districts of Lebanon which were selected randomly covering different socioeconomic status and demographic characteristics. This gives each member of the targeted population an equal chance to be selected.

Parents/Guardians of adolescents gave a written consent after getting detailed information from the study coordinators and reviewed the consent content.

Data were collected by using a self-administered questionnaire. The questions included demographic data consisting of gender, parental level of education (Illiterate, Elementary, Intermediate/Secondary, and University/ post graduate), heights and weights. Heights and weights were measured and recorded by the research coordinators. Overweight was defined as BMI between the $85^{\text {th }}$ and $95^{\text {th }}$ percentile. Obesity was defined as BMI greater than the $95^{\text {th }}$ percentile for age and gender derived from the U.S First National Health and Nutrition Examination Survey [13].

Social and physical activities as well as school performance were measured using the competence scale, which includes activities and social scales. The physical activity scale included the number of sports performed by the adolescents, the mean of participation and skill in sports; it also included the mean of participation and skill in activities other than sports, as well as jobs performed by the adolescents inside or outside the house, both paid and unpaid. The total score for the activity scale is the sum of the 5 scores entered for the items of the activity scale. The Child Behavior Checklist (CBCL) is a rating scale developed by Achenbach and coworkers for assessing social competence and behavior/ emotional problems in children. The CBCL is filled out by parents. Today it has been translated into 69 different languages and has been used in numerous international studies on a wide range of problems in adolescents (14). It also has been used in a number of epidemiological studies, including the Scandinavian countries. In several cross-cultural studies, populations from different countries have been compared using the CBCL. Thus, the CBCL is an international instrument well validated in broad population-based studies as well as in studies on children and adolescents with general psychiatric disorders, living in psychosocial risk situations and with specific neurological or neuropsychiatric disorders. However the CBCL is primarily focused on general behavior problems and psychiatric symptoms. For the activities section (Activities such as sports, social as with contact with friends and school as participation in classroom) the scale is $20-65$ where 35 is borderline clinical case and 30 is clinical case, any score above 35 is normal. The psychiatric section is divided into internalizing behavior: anxiety and withdrawal, both have scale from 50-100 where 65 is borderline clinical case and 70 is a clinical case, anything below 65 is normal.

The social scale included the number of organizations in which the adolescent participates in, and the number of friends, and the presence, and constancy of contact with friends. The child's behavior with others, including his siblings, parents and friends was also assessed, and finally whether the child plays or works alone. The total score for the social scale is obtained by adding up the scores of the listed items.

\section{Statistical Analysis}

Statistical analysis was performed using SPSS 22.0 software (SPSS Inc., Chicago, IL, USA). Data are presented as numbers (percentages). Fisher exact test was used to assess any significant difference for activities and social scores within female and male adolescents, in addition to anxiety scores. P-Values less than 0.05 were considered significant.

\section{Results}

A total of 587 adolescents were entered for final data analysis with a response rate of $69.57 \%$. Two hundred thirty one adolescents $(47.4$ $\%)$ were males and two fifty six adolescents $(52.6 \%)$ were females. Overall, $10.5 \%$ of participants were obese (Table1).

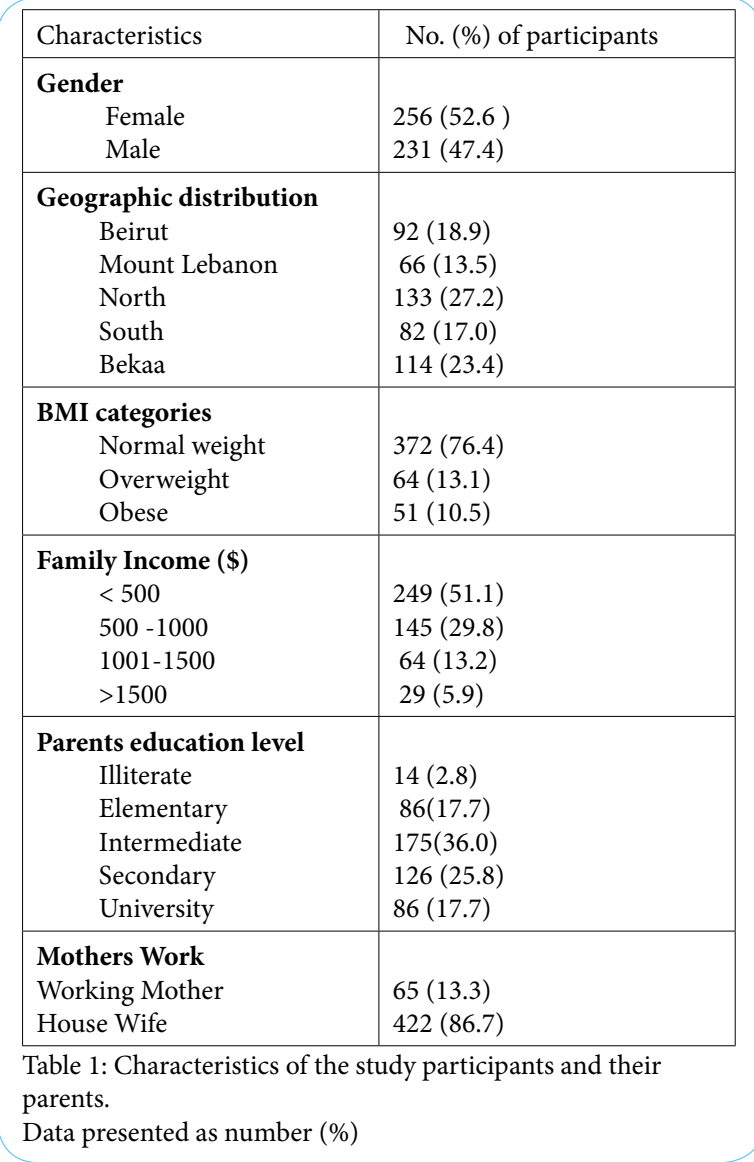

The percentage of adolescents who did not participate in any sports reached up to $102(21.0 \%)$. Moreover, 67 (13.8\%) participants had no 
Citation: Al-Tannir M, Assi NA, Abu-Shaheen AK, Altannir Y (2016) Obesity Associations with Behavior and Anxiety in Lebanese Adolescents. Int J Clin Res Trials 1: 104. doi: https://doi.org/10.15344/2456-8007/2016/104

Page 3 of 5

hobbies and 104 (21.4\%) of them did not help at home. In addition, 21 (4.4\%) adolescents are always lonely.

Activity score, as part of the competence scale, showed that 77 (15.9\%) had activity scores below normal. Moreover, borderline scores were shown in $35(7.1 \%)$ participants. Activity scores had significantly increased with increasing age among females $(\mathrm{P}=0.03)$. Whereas, there was no change in activity scores with increasing age among obese and overweight boys.

Social score is the second part of the competence scale, showed that obesity is significantly associated with low level of social activities only among female adolescents.

The assessment of signs of withdrawal revealed that 5 out of 31 obese males (16.1\%) and 3 out of 20 obese females (15.0\%) had clinical case (Table 2). There was no statistical significant difference among obese, overweight and normal weight participants of both genders concerning the withdrawal and anxiety \depression scales (Table 2 and Table 3 ). lifestyle for countries in transition are key factors affecting nutritional habits and obesity levels. Moreover, sociocultural norms in some Arab countries, where rich high-fat food plays an important role in the daily diet and where "plumpness" is considered healthy and a sign of beauty and affluence have been suggested as underlying factors in the alarmingly high prevealence of obesity in the region [22-25]. Current studies on food consumption patterns of the Lebanese young and adult population show a shift in the food consumption toward increased intake of fat, milk, and animal protein, and a decrease in the intake of complex carbohydrates, in particular, bread and cereal. The contribution of carbohydrates to daily energy intake decreased from $64.8 \%$ in 1963 to $52.9 \%$ in 1998 , whereas the contribution of fat increased from $24 \%$ to $34.3 \%$ during the same period [26].

On the other hand, social and physical activities were not affected in our adolescents. This could be explained by the importance of family support and acceptance of the obese adolescent, which helps him / her to be as competent and socially interactive as his non-obese peers [27]. This scale affects perceived competence and social acceptance,

\begin{tabular}{|c|c|c|c|c|c|c|c|c|}
\hline \multirow[t]{3}{*}{ Withdrawal } & \multicolumn{8}{|c|}{ Gender } \\
\hline & \multicolumn{4}{|c|}{ Male } & \multicolumn{4}{|c|}{ Female } \\
\hline & $\begin{array}{l}\text { Normal } \\
\text { weight }\end{array}$ & $\begin{array}{l}\text { Over } \\
\text { weight }\end{array}$ & obese & $\mathrm{p}$ - value & $\begin{array}{l}\text { Normal } \\
\text { weight }\end{array}$ & $\begin{array}{l}\text { Over } \\
\text { weight }\end{array}$ & obese & $\mathrm{p}$-value \\
\hline Normal & $114(67.9)$ & $20(62.5)$ & $22(71.0)$ & 0.756 & $141(69.1)$ & $21(65.6)$ & $15(75.0)$ & 0.995 \\
\hline Borderline & 35 (20.8) & $8(25.0)$ & $4(12.9)$ & & $31(15.2)$ & $5(15.6)$ & $2(10.0)$ & \\
\hline Clinical case & $19(11.3)$ & $4(12.5)$ & $5(16.1)$ & & $32(15.7)$ & $6(18.8)$ & $3(15.0)$ & \\
\hline
\end{tabular}

Table 2: Withdrawal scores of the study participants among both gender and BMI categories.

Data presented as number (\%)

\begin{tabular}{|c|c|c|c|c|c|c|c|c|}
\hline \multirow{3}{*}{$\begin{array}{l}\text { Anxiety } \backslash \\
\text { Depression }\end{array}$} & & \multicolumn{7}{|c|}{ Gender } \\
\hline & & \multicolumn{3}{|c|}{ Male } & \multicolumn{4}{|c|}{ Female } \\
\hline & Normal weight & Over weight & obese & $\mathrm{p}$-value & Normal weight & Over weight & obese & $\mathrm{p}$-value \\
\hline Normal & $116(69.0)$ & $21(65.6)$ & $21(67.7)$ & \multirow[t]{3}{*}{0.745} & $163(79.9)$ & $19(59.4)$ & $13(65.0)$ & \multirow[t]{3}{*}{0.084} \\
\hline Borderline & $21(12.5)$ & $5(15.6)$ & $2(06.5)$ & & $12(05.9)$ & $3(09.4)$ & $2(10.0)$ & \\
\hline Clinical case & $31(18.5)$ & $6(18.8)$ & $8(25.8)$ & & $29(14.2)$ & $10(31.3)$ & $5(25.0)$ & \\
\hline
\end{tabular}

Table 3: Anxiety \Depression scores of the study participants among both gender and BMI categories.

Data presented as number (\%)

\section{Discussion}

The main findings of this survey demonstrated that obesity is significantly associated with low level of social activities only among female adolescents whereas academic, general activities were not affected in both genders. This may be explained by the study of Erickson et.al who argued that depressive symptoms in adolescents could be attributed to the existence of a relationship between depressive symptoms and BMI [3]. This finding is in accordance with a study done by Doyle et al, which showed that overweight adolescents experienced increased level of negative affect [15]. In countries of the Eastern Mediterranean Region (EMR), health professionals similarly caution against a major surge in obesity rates. For example, the prevalence of obesity among women in Kuwait is $~ 40 \%$, which places the country among the highest rates in the world [16]. A study performed in selected countries of the (EMR) region [17-21] demonstrated that obesity does not seem to be a characteristic of solely affluent societies. Modernization and adoption of the Western but similar competence among our adolescents could be explained by the involvement of other factors than obesity itself regarding this issue. This finding is in contrary to the conclusion drawn by Davison and Birch [28]. Our main reason to measure and record the heights and weights by ourselves is to eliminate the self-reporting bias given that being female and being overweight have been associated with the underestimation of BMI. Further, underreporting among girls has been shown to increase over adolescence into adulthood. Efforts are needed to give support for obese female adolescents perhaps by eating disorder preventive programs that are suitable for this gender at this age category.

In recent years, more concern has been directed toward childhood obesity [29]. Studies indicate that the higher the childhood BMI percentile, the greater the risk of becoming an overweight adult [30], and that obesity in adults can now be predicted from earlier childhood and adolescent weight $[31,32]$. As adult obesity is difficult to treat, identification at an early age of individuals who are at a high 
risk of obesity becomes especially important because it allows for introduction of early preventive strategies [33].

Our results showed that overall $10.5 \%$ of participants were obese. Moreover, boys were at greater risk of overweight and obesity than girls. Our results are also comparable to those obtained from a previous study conducted on Lebanese boys and girls, where overall $6.6 \%$ of public schools adolescents were obese, while $20.5 \%$ were at risk of obesity [34].

The potential limitation in this study is due to the cross-sectional nature of the study design, therefore the causal inferences cannot be made. Moreover, this study include self-report of physical activity, which tends to overestimate actual activity levels particularly at lower levels of activity [5]. The fluctuation in correlations may be an artifact of the change in questionnaire collection protocol. Future studies using data from an electronic physical activity monitor and dietary assessment coded for removal of beverages for multiple energy density calculations would better identify the extent of the trends uncovered here. Longitudinal data from a broader age group could additionally determine if our discovered trends continue with age guiding obesity prevention in the general population. Despite these factors, this epidemiological study contributes additional knowledge to the national data addressing overweight, obesity, and associated covariates in the Lebanese population. We randomly approached and invited a representative sample of 700 adolescents over a 5-month period from 10 schools located in all 5 districts of Lebanon which were selected randomly covering different socioeconomic status and demographic characteristics. This gives each member of the targeted population an equal chance to be selected. Moreover, Lebanon does not have the home-schooled students program and has minimum dropouts in this age category which may assure the comparability to those who did not participate. Nevertheless, sampling error referred as natural variations between samples in never eliminated. Thus, these justifications could promise the similarity among adolescents who participated and those who refused. The study used standardized international guidelines for definition of overweight and classes of obesity, which allowed comparisons with similar reports from other countries. Moreover, the study focused attention on obesity in adolescents, an often-neglected subpopulation in research and policy in the region.

Whereas further studies are needed for examination of the sociocultural, economic, and behavioral factors associated with BMI and weight gain in Lebanon, now is the time to start implementing multicomponent interventions, at the societal and individual level, for weight control. Health professionals may play a key role in promoting regular physical activity. Other means of interventions may use mass media to influence nutritional norms, practices, and personal choices. Such interventions aimed at better health awareness and more physical activity should be monitored for their effectiveness over the years.

\section{Conclusion}

In conclusion, obesity among Lebanese adolescents is significantly associated with decreased social activity level among females and imposes a health concern for both genders in later years. The alarming increase in obesity in the juvenile population today, consequently bodes ill for obesity and subsequent health odds for the generation to come. These bleak odds, in conjunction with our findings, stress the importance of attention to health habits in children when the framework of health behaviors is less settled and body composition is more responsive.

\section{Competing Interests}

The author declares that he has no competing interests.

\section{References}

1. Huang JS, Norman GJ, Zabinski MF, Calfas K, Patrick K (2007) Body image and self-esteem among adolescents undergoing an intervention targeting dietary and physical activity behaviors. J Adolesc Health 40: 245-251.

2. van den Berg PA, Mond J, Eisenberg M, Ackard D, Neumark-Sztainer D (2010) The Link Between Body Dissatisfaction and Self-Esteem in Adolescents: Similarities Across Gender, Age, Weight Status, Race/Ethnicity, and Socioeconomic Status. J Adolesc Health 47: 290-296.

3. Mond J, van den Berg P, Boutelle K, Hannan P, Neumark-Sztainer D (2011) Obesity, body dissatisfaction, and emotional well-being in early and late adolescence: findings from the project EAT study. J Adolesc Health 48: 373 378.

4. Salwen JK (2015) The impact of weight-related abuse on self-perception and disordered eating: A model of obesity (Doctoral dissertation, State University Of New York At Stony Brook).

5. Klockziem TY (2015) Effect of a Lifetime Health and Fitness Class on College Students (Doctoral dissertation, WALDEN UNIVERSITY).

6. Machado BC, Gonçalves SF, Martins C, Brandão I, Roma-Torres A, et al. (2016) Anorexia nervosa versus bulimia nervosa: differences based on retrospective correlates in a case-control study. Eat Weight Disord 21:185197.

7. Achenbach TM (2005) Advancing assessment of children and adolescents: commentary on evidence-based assessment of child and adolescent disorders. J Clin Child Adolesc Psychol 34: 541-547.

8. Achenbach TM, Ruffle TM (2000) The Child Behavior Checklist and related forms for assessing behavioral/emotional problems and competencies. Pediatr Rev 21: 265-271.

9. Tanas R, Caggese G, Marucci S (2015) Future directions in prevention and treatment of children obesity and eating disorders. Italian Journal of Pediatrics 41(Suppl 2), A72.

10. World Health Organization (2003) Health System and Performance in Lebanon Ministry of Public Health Beirut, Lebanon Web of Science ${ }^{\circledR}$ Times Cited: 812.

11. U.S. Census Bureau U.S. (2002) Census Data Available online.

12. Sibai AM, Fletcher A, Hills M, Campbell O (2001) Non-communicable disease mortality rates using the verbal autopsy in a cohort of middleaged and older populations in Beirut during wartime, 1983-93. J Epidemiol Community Health 55: 271-276.

13. [No authors listed] (1995) Physical status: the use and interpretation of anthropometry. Report of a WHO Expert Committee. World Health Organ Tech Rep Ser 854: 1-452.

14. Sibai AM, Hwalla N, Adra N, Rahal B (2003) Prevalence and covariates of obesity in Lebanon: findings from the first epidemiological study. Obes Res 11: 1353-1361.

15. Doyle AC, le Grange D, Goldschmidt A, Wilfley DE (2007) Psychosocial and physical impairment in overweight adolescents at high risk for eating disorders. Obesity (Silver Spring) 15: 145-154

16. Kandela P (1999) The Kuwaiti passion for food cannot be shaken. Lancet 353: 1249.

17. al-Isa AN (1995) Prevalence of obesity among adult Kuwaitis: a crosssectional study. Int J Obes Relat Metab Disord 19: 431-433.

18. al-Nuaim AR, al-Rubeaan $\mathrm{K}$, al-Mazrou $\mathrm{Y}$, al-Attas $\mathrm{O}$, al-Daghari $\mathrm{N}$, et al (1996) High prevalence of overweight and obesity in Saudi Arabia. Int J Obes Relat Metab Disord 20: 547-552.

19. Ajlouni K, Jaddou H, Batieha A (1998) Obesity in Jordan. Int J Obes Relat Metab Disord 22: 624-628.

20. Musaiger AO, Radwan HM (1995) Social and dietary factors associated with obesity in university female students in United Arab Emirates. J R Soc Health 115: 96-99. 
Citation: Al-Tannir M, Assi NA, Abu-Shaheen AK, Altannir Y (2016) Obesity Associations with Behavior and Anxiety in Lebanese Adolescents. Int J Clin Res Trials 1: 104. doi: https://doi.org/10.15344/2456-8007/2016/104

Page 5 of 5

21. Abdul-Rahim HF, Abu-Rmeileh NM, Husseini A, Holmboe-Ottesen G, Jervell $\mathrm{J}$, et al. (2001) Obesity and selected co-morbidities in an urban Palestinian population. Int J Obes Relat Metab Disord 25: 1736-1740.

22. Nasser M (1986) Comparative study of the prevalence of abnormal eating attitudes among Arab female students of both London and Cairo universities. Psychol Med 16: 621-625.

23. al-Isa AN (1997) Body mass index and prevalence of obesity changes among Kuwaitis. Eur J Clin Nutr 51: 743-749.

24. Al Shammari SA, Khoja TA, Subaie AS (1994) Transcultural attitude towards being overweight in patients attending health centers, Riyadh, Saudi Arabia. Family Pract Res J 14: 149-156.

25. Mehio-Sibai A, Kanaan N, Chaaya M, Rahal B, Abdullah A, et al. (2003) Ethnic differences in weight loss behavior among secondary school students in Beirut: the role of weight perception. Soz Praventivmed 48: 234-241.

26. Baba NH (2000) Dietary intake and nutrition related disorders in Lebanon Nutr Health 14: 33-40.

27. Epstein LH (1996) Family-based behavioural intervention for obese children. Int J Obes Relat Metab Disord 20 Suppl 1: S14-21.

28. Davison KK, Birch LL (2001) Weight status, parent reaction, and self-concept in five-year-old girls. Pediatrics 107: 46-53.

29. Ebbeling CB, Pawlak DB, Ludwig DS (2002) Childhood obesity: public-health crisis, common sense cure. Lancet 360: 473-482.

30. Guo SS, Wu W, Chumlea WC, Roche AF (2002) Predicting overweight and obesity in adulthood from body mass index values in childhood and adolescence. Am J Clin Nutr 76: 653-658.

31. Serdula MK, Ivery D, Coates RJ, Freedman DS, Williamson DF, et al. (1993) Do obese children become obese adults? A review of the literature. Prev Med 22: 167-177.

32. Bray GA (2002) Predicting obesity in adults from childhood and adolescent weight. Am J Clin Nutr 76: 497-498.

33. Labarthe DR Eissa M, Varas C (1991) Childhood precursors of high blood pressure and elevated cholesterol. Annu Rev Public Health 12: 519-541.

34. Sibai AM, Hwalla N, Adra N, Rahal B (2003) Prevalence and covariates of obesity in Lebanon: findings from the first epidemiological study. Obes Res 11: $1353-1361$ 